\title{
COVID-19-induced low power demand and market forces starkly reduce $\mathrm{CO}_{2}$ emissions
}

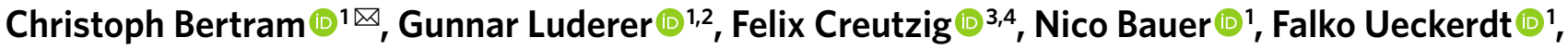 \\ Aman Malik (D) 1,2 and Ottmar Edenhofer (iD) 1,3,5
}

\begin{abstract}
The COVID-19 pandemic continues to strongly affect global energy systems. Global power sector $\mathrm{CO}_{2}$ emissions have shown a substantial decline, thanks to (a) the COVID-19induced economic downturn and resulting reduction of electricity demand and (b) a decrease of carbon intensity of power generation as coal generation is decreased most strongly. These effects illustrate the opportunity for different policies to support a structural and accelerating decline of power sector emissions.
\end{abstract}

Even before the COVID-19 pandemic and its impact on the energy system and $\mathrm{CO}_{2}$ emissions ${ }^{1}$, the power sector was amidst a dynamic transformation process. While fossil fuels (predominantly coal and gas) are used to generate most power in most countries, renewable energies dominate the growth of global power generation (Fig. 1a,b and Extended Data Fig. 1). The uptake of wind and solar was concentrated in a few markets with substantial support policies in place in the early 2010s, but has become much more widespread in recent years after continued reductions in technology costs and improvements in performance ${ }^{2}$.

In this situation, the moderate reduction in electricity demand stemming from both direct restrictions on industry, commerce and other activities and the overall economic downturn has had a particularly strong impact on power sector emissions. Real-time generation data by fuel up to the end of September are available for India $^{3}$, the USA ${ }^{4}$ and Europe ${ }^{5}$, which together accounted for $34 \%$ of global $\mathrm{CO}_{2}$ emissions from power generation in 2019 (ref. ${ }^{6}$ ). In these three markets, monthly electricity demand has declined by up to $20 \%$ compared with 2019 , while the monthly $\mathrm{CO}_{2}$ emissions from the power sector have decreased by up to $50 \%$ (Fig. 2). The reason is the so-called merit-order of the capacity mix of different generation technologies. If demand decreases, plants with the highest variable costs are switched off first. Fossil-fuel-based power plants incur costs from burning fuels to generate electricity. However, the costs of renewable and nuclear power are dominated by the construction of the plants, so these technologies are characterized by low variable costs per kWh and thus operate even under reduced demand. This merit-order mechanism induces an asymmetry against fossil fuels in the electricity generation mix, and therefore $\mathrm{CO}_{2}$ emissions decrease more strongly than electricity demand.

Even within fossil generation, reductions in coal power generation have been greater than those in power generation using natural gas (Extended Data Fig. 2), increasing the downward trend of coal use in Organisation for Economic Co-operation and Development (OECD) countries. This is counterintuitive, as traditionally natural gas power plants are thought to be less favourably placed on the merit order, due to higher fuel costs. However, the overall economic downturn has reduced demand for oil and natural gas in all sectors, so that spot-market prices for gas have declined, favouring gas-powered generation. Coal prices have also declined, but with a smaller impact on the variable costs of coal-based power generation, due to higher shares of extraction- and transportation-related costs as well as higher maintenance costs. The effect of switching from coal to gas has additionally been supported in Europe by relatively stable emissions prices in the EU Emissions Trading System (EU-ETS), which has contributed further to unfavourable economics for coal-based power generation ${ }^{7}$.

With assumptions on 2020 demands based on International Monetary Fund (IMF) gross domestic product (GDP) projections $^{8}$ and reduced yearly addition of low-carbon generation (Fig. 1b), we estimate yearly $\mathrm{CO}_{2}$ emissions from the power sector to be $6.8 \%$ [4.9-9.0\%] lower than in 2019 (Fig. 1c). This reduction is much larger than previously estimated by Le Quéré et al. ${ }^{1}(1.5 \%$ [0.3-3.1\%] power sector emissions reduction in their scenario $S 3$, see also Methods) but roughly in line with an updated version of their daily model that we calibrated to the observed emissions reductions in Europe, India and the USA until the end of September (Supplementary Fig. 2), estimating yearly reductions of $7.5 \%$ [5.3-10.1\%] for the power sector (see Supplementary Information). The global reduction results from strong reductions of fossil generation in most countries, partly offset by increases in China (Extended Data Fig. 1). As a result, the share of China in global power system $\mathrm{CO}_{2}$ emissions strongly increases to $39 \%$ in 2020 , from $37 \%$ in 2019.

If the annual net addition of low-carbon generation (from wind, solar, nuclear and hydro) surpasses the increase in power demand, total fossil generation decreases. During most of the last decade, annual demand growth has slightly surpassed the additional generation of low-carbon power, except for 2015 and 2019 (Fig. 1b). The central estimate of the latest World Economic Outlook by the $\mathrm{IMF}^{8}$ projects $2021 \mathrm{GDP}$ levels to be equal to the 2019 level, after a strong dip in 2020. Based on the strong coupling between economic growth and power demand (Supplementary Fig. 3), electricity demand is likely to remain at or below 2019 levels at least until the end of 2021. On the other hand, the build-up of low-carbon power capacity is expected to continue in the near and longer-term future, with only a slight deceleration in 2020 , mostly caused by a reduction of nuclear generation in Europe ${ }^{9}$. This leads to a continuing decrease of emissions intensity per $\mathrm{kWh}$ of power generation, with a steep drop in 2020 (Extended Data Fig. 3). To the extent that

'Potsdam Institute for Climate Impact Research, Member of the Leibniz Association, Potsdam, Germany. ${ }^{2}$ Global Energy Systems Analysis, Technische Universität Berlin, Berlin, Germany. ${ }^{3}$ Mercator Research Institute on Global Commons and Climate Change, Berlin, Germany. ${ }^{4}$ Sustainability Economics of Human Settlements, Technische Universität Berlin, Berlin, Germany. ${ }^{5}$ Economics of Climate Change, Technische Universität Berlin, Berlin, Germany. 凶e-mail: bertram@pik-potsdam.de 


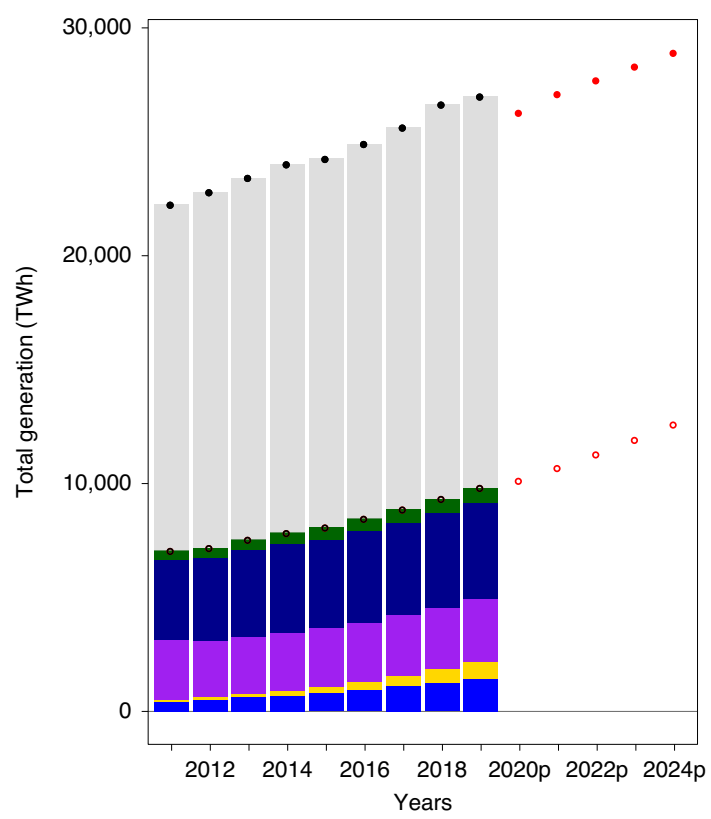

b

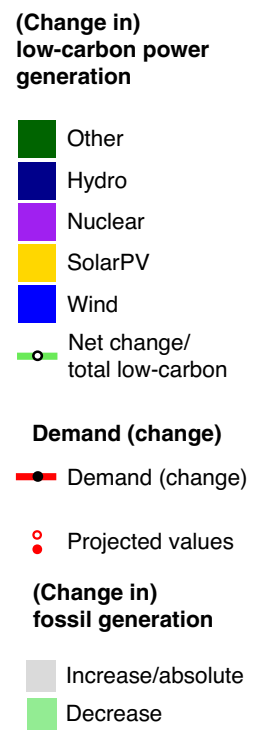

(Change in) generation

Decrease

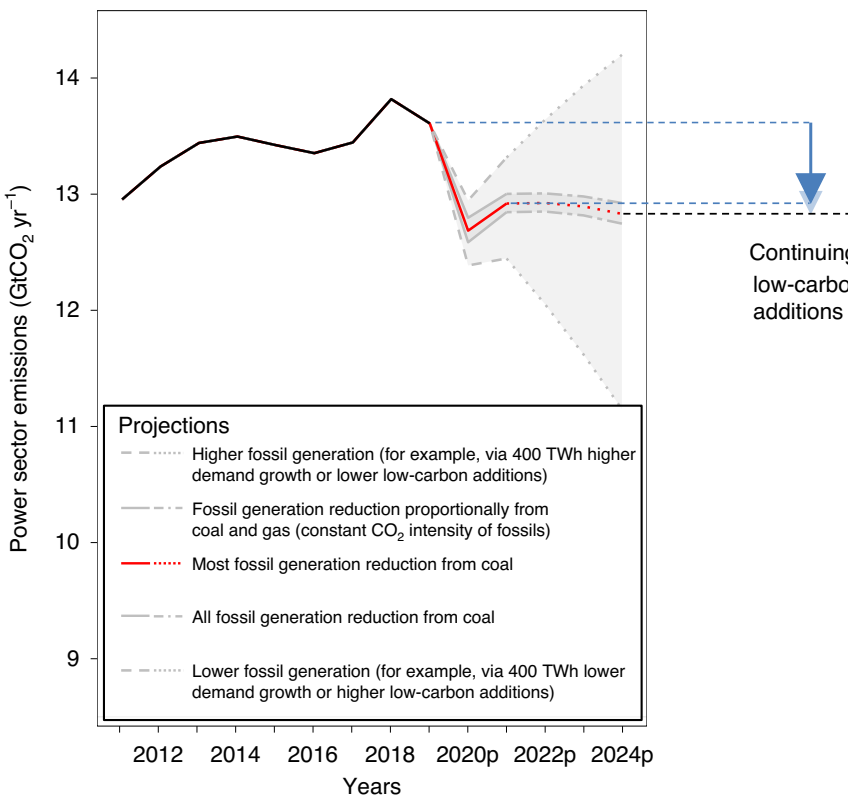

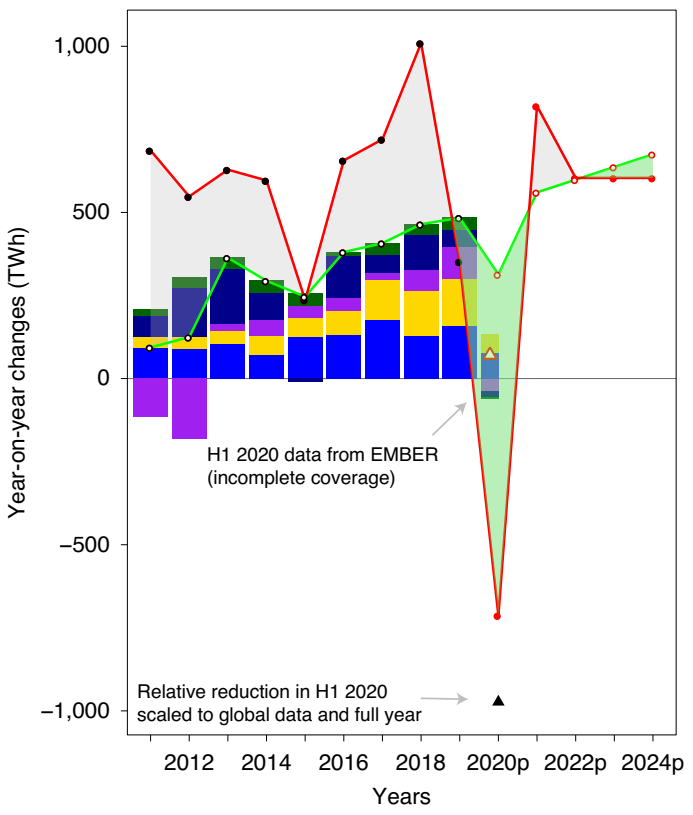

d

Determinants of 2021-2024 trajectory

Potential reasons for emissions comeback (upward arrows) or accelerated emissions decline (downward arrows)

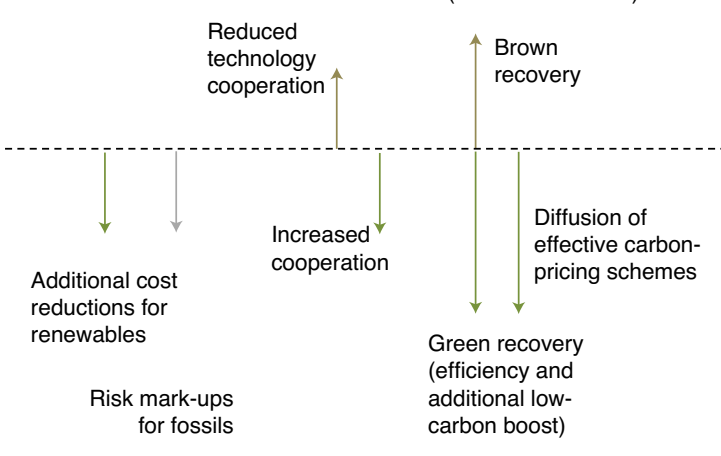

Depends on policy action

Fig. 1 | Historical evolution of global power generation and $\mathrm{CO}_{2}$ emissions, and projections until 2024. a, Absolute values for each year, with low-carbon technologies shown separately (coloured bars) and aggregated (circles). p, projection. b, Year-on-year changes of power generation by individual low-carbon technologies (coloured bars), their total net change (white dots and green line) and total power generation as a proxy for demand (black dots and red line). The shaded areas indicate increases (grey) and decreases (green) of residual fossil generation. c, Power sector emissions from 2011 to 2019 , and projections for 2020-2024 based on the power system evolution in $\mathbf{a}$ and $\mathbf{b}$ (note that the $y$-axis scale does not start at zero). $\mathbf{d}$, Qualitative analysis of key factors determining the near-term evolution of global power sector $\mathrm{CO}_{2}$ emissions. For details on data sources and projections, see Methods.

the growth in low-carbon power generation exceeds future demand increases, power supply emissions may have reached their all-time peak in 2018 (central estimate in Fig. 1c). Power sector emissions in 2021 will likely increase compared with 2020 but remain below 2019 values, given continuing additions of low-carbon generation (Fig. 1c, blue arrow).

If the rate of low-carbon additions increases through 2022 and beyond, and assuming that demand growth rates in 2022-2024 return to average levels over past years (which are similar to near-term yearly increases expected by the International Energy Agency $(\text { IEA })^{10}$ ), a cross-over point would be reached. Passing this point would mean a structural transition from growing to decreasing fossil power generation. $\mathrm{CO}_{2}$ emissions would thus decline from 2018 onwards based on underlying drivers, accelerated by the COVID-19 pandemic. If demand increases faster, or low-carbon growth slows considerably, fossil fuel generation and emissions 


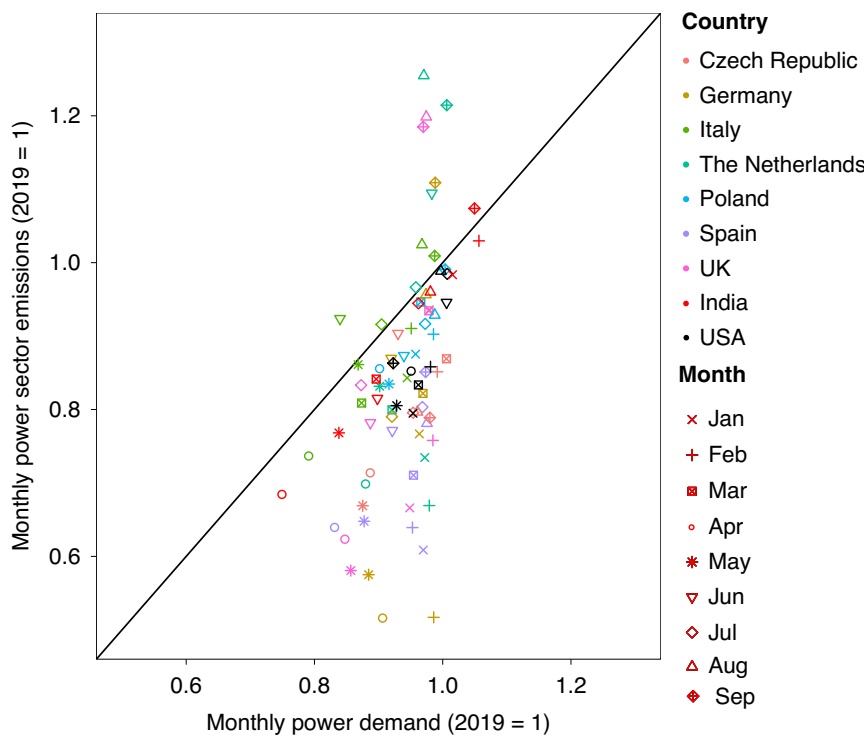

Fig. 2 | Monthly power demand and emissions in $\mathbf{2 0 2 0}$ relative to 2019. Emissions calculated from fossil generation data by fuel for European countries with highest power sector emissions from the European Network of Transmission System Operators for Electricity (ENTSO-E). Indian data from carbontracker.in. US data from the Energy Information Administration, calculated from fossil generation data by fuel. February data are adjusted to account for the leap year 2020.

could continue to increase through 2024, but would reach the 2018 peak level only with very high demand increases or very low additions of low-carbon generation.

Figure 1c contrasts the central estimate, assuming the demand and low-carbon additions as in Fig. 1a,b, and assuming constant emissions intensity of fossil power generation, with alternative projections. These vary the carbon intensity of fossil generation, and the overall amount of fossil generation (which given the merit-order structure is determined by both absolute power demand and low-carbon generation). Emissions could return to the levels of the 2018 peak by 2024 if demand increases are 400 TWh per year higher (or annual low-carbon additions are 400 TWh lower, or any combination leading to a $400 \mathrm{TWh}$ per year net difference for fossil generation), while a very fast emissions decline is possible if demand increases are $400 \mathrm{TWh}$ lower per year (or low-carbon addition is 400 TWh higher).

Various market factors affect the projections (Fig. 1d). A disruption in supply chains, reduced availability of capital investments and reduced international technology cooperation would hurt low-carbon power addition and deployment of energy efficiency technologies, especially in emerging economies ${ }^{11}$. Existing plans to expand the fleet of coal-based power plants ${ }^{12}$ face very immediate risks of resulting in stranded assets, both due to fast technological change and climate change considerations ${ }^{13,14}$. The current situation illustrates the weakening market position of coal-power generation, suffering simultaneously from reductions in power prices and from an unfavourable position on the merit order compared with low-carbon alternatives, resulting in strongly reduced market share. This demonstration of the low resilience of coal will make it more difficult for future projects to access financing, in turn increasing the attractiveness of low-carbon projects. Lastly, any delay of investment decisions for power generation expansion makes renewable energy projects more attractive, as the costs of wind, solar and storage ${ }^{15}$ continue to decrease.

It is clear that the post-crisis developments will be strongly impacted by near-term policy choices. There is a distinct risk that brown recovery packages will give support to construction of additional fossil-fuelled power plants. These are, however, very risky investments, as the rate of utilization of coal-fuelled power plants has been decreasing in nearly all markets over recent years and plummeted amid the pandemic in $2020^{\circ}$ (see above). Only with a very strong rebound of demand and indiscriminate support also for inefficient industries would fossil generation be able to expand back to 2018 levels, but it would be the first to lose market share in repeated suppression of demand, due to either crises or increased efficiency.

Inversely, the current situation offers a unique opportunity for policy-makers to make the decreasing trend in power sector emissions irreversible, while total electricity generation continues to grow. The most effective means for accelerating the transformation of the power system is to strengthen carbon pricing around the world and to eliminate subsidies for fossil fuels. The current situation of very low fossil fuel prices offers a good opportunity for these measures, especially if revenue recycling is used to support other societal goals ${ }^{16}$. Experience from the UK minimum price and recent auction price increases in the EU-ETS show that moderate carbon prices of around $\$ 20$ per $\mathrm{t} \mathrm{CO}_{2}$ are already effective in reducing power sector emissions considerably ${ }^{7,17}$. An important characteristic of carbon pricing, making it indispensable in the medium term, is that it counteracts the consumer price reductions of fossil fuels resulting from their reduced usage ${ }^{18}$.

A complementary way to support power sector decarbonization can make use of the merit-order mechanism described above. Supporting investments in low-carbon power generation, especially fast-growing granular power technologies such as wind and solar ${ }^{19}$, and increasing energy efficiency reduces the residual demand for fossil power generation. Both of these measures have the additional benefits of high readiness, fast scalability, high employment intensity and local value added. Furthermore, policies supporting behavioural, social and structural changes reduce energy demand for attaining service levels and thus reduce future electricity demand growth ${ }^{20}$, resulting in decreased import bills for energy importers.

International cooperation is key to help fast-growing economies outside the OECD to quickly scale up these two options, thus also reaching peak emissions as soon as possible (Extended Data Fig. S1) and avoid additional carbon lock-in. Long-term investment funds (supported for example by the EU) could provide credit below the high market interest rates in developing countries, thereby reducing the high capital costs of low-carbon power generation technologies and investments in energy efficiency. These support schemes should incentivize developing countries to introduce carbon pricing schemes in order to avoid risky rebound effects at all scales, by which depressed world market prices for fossil fuels could lead to increased use of these fuels in unregulated regions ${ }^{21}$ and sectors ${ }^{22}$. If designed properly, these schemes can enhance international cooperation significantly ${ }^{23}$ and contribute to fostering sustainable development post COVID-19 globally.

The power sector has a crucial role to play in the decarbonization of the entire energy system and was already in the midst of a dynamic transformation process before COVID-19. The economic repercussions of the pandemic have led to a very pronounced reduction of fossil-fuel-based power generation, illustrating the risks of stranded assets in coal power generation to financial actors. While the uncertainties on near-term projections are considerable, it is possible that power sector $\mathrm{CO}_{2}$ emissions will not return to their level of 2018 (ref. ${ }^{24}$ ). Various policy instruments could be effective in supporting an accelerated emissions decline over the next few years.

\section{Online content}

Any methods, additional references, Nature Research reporting summaries, source data, extended data, supplementary information, acknowledgements, peer review information; details of 
author contributions and competing interests; and statements of data and code availability are available at https://doi.org/10.1038/ s41558-021-00987-x.

Received: 27 August 2020; Accepted: 13 January 2021; Published online: 8 February 2021

\section{References}

1. Le Quéré, C. et al. Temporary reduction in daily global $\mathrm{CO}_{2}$ emissions during the COVID-19 forced confinement. Nat. Clim. Change 10, 647-653 (2020).

2. Creutzig, F. et al. The underestimated potential of solar energy to mitigate climate change. Nat. Energy 2, 17140 (2017).

3. The CSEP Electricity and Carbon Tracker https://carbontracker.in/ (2020).

4. Open data. US Energy Information Administration https://www.eia.gov/ opendata/qb.php?category $=3390105 \&$ sdid=EBA.US48-ALL.NG.COL.H (2020).

5. ENTSO-E Transparency Platform https://transparency.entsoe.eu/ (2020).

6. Statistical Review of World Energy 2020. BP https://www.bp.com/en/global/ corporate/energy-economics/statistical-review-of-world-energy/downloads. html (2020).

7. Matthes, F., Hermann, H. \& Mendelevitch, R. Assessment of the planned compensation payments. Öko-Institut e.V. https://www.oeko.de/fileadmin/ oekodoc/Assessment-of-the-planned-compensation-payments.pdf (2020).

8. World Economic Outlook: A Long and Difficult Ascent (IMF, 2020).

9. Wind and Solar Now Generate One-Tenth of Global Electricity. Ember https://ember-climate.org/wp-content/uploads/2020/08/ Report-Ember-Global-Electricity-Review-H1-2020.pdf (2020).

10. World Energy Outlook 2019. IEA https://www.iea.org/reports/ world-energy-outlook-2019 (2019).

11. Cherp, A. \& Jewell, J. COVID-19 weakens both sides in the battle between coal and renewables. Behavioural and Social Sciences at Nature Research $\mathrm{http} / / /$ socialsciences.nature.com/users/390808-aleh-cherp/posts/66644-by-disr upting-technology-diffusion-and-supply-chains-covid-19-may-harm-renewables-morethan-coal-but-still-weaken-coal-lock-in-in-developing-countries (2020).
12. Edenhofer, O., Steckel, J. C., Jakob, M. \& Bertram, C. Reports of coal's terminal decline may be exaggerated. Environ. Res. Lett. 13, 024019 (2018).

13. Mercure, J.-F. et al. Macroeconomic impact of stranded fossil fuel assets. Nat. Clim. Change 8, 588-593 (2018).

14. Malik, A. et al. Reducing stranded assets through early action in the Indian power sector. Environ. Res. Lett. 15, 094091 (2020).

15. Schmidt, O., Hawkes, A., Gambhir, A. \& Staffell, I. The future cost of electrical energy storage based on experience rates. Nat. Energy 2 , 17110 (2017).

16. Franks, M., Lessmann, K., Jakob, M., Steckel, J. C. \& Edenhofer, O. Mobilizing domestic resources for the Agenda 2030 via carbon pricing. Nat. Sustain. 1, 350-357 (2018).

17. Wilson, I. A. G. \& Staffell, I. Rapid fuel switching from coal to natural gas through effective carbon pricing. Nat. Energy 3, 365-372 (2018).

18. Bauer, N. et al. Global fossil energy markets and climate change mitigation - an analysis with REMIND. Climatic Change 136, 69-82 (2016).

19. Wilson, C. et al. Granular technologies to accelerate decarbonization. Science 368, 36-39 (2020)

20. Grubler, A. et al. A low energy demand scenario for meeting the $1.5^{\circ} \mathrm{C}$ target and sustainable development goals without negative emission technologies. Nat. Energy 3, 515-527 (2018).

21. Bauer, N. et al. $\mathrm{CO}_{2}$ emission mitigation and fossil fuel markets: dynamic and international aspects of climate policies. Technol. Forecast. Soc. Change A $\mathbf{9 0}$, 243-256 (2015).

22. Bertram, C. et al. Complementing carbon prices with technology policies to keep climate targets within reach. Nat. Clim. Change 5, 235-239 (2015).

23. Kornek, U. \& Edenhofer, O. The strategic dimension of financing global public goods. Eur. Econ. Rev. 127, 103423 (2020).

24. World Energy Outlook 2020. IEA https://www.iea.org/reports/ world-energy-outlook-2020 (2020).

Publisher's note Springer Nature remains neutral with regard to jurisdictional claims in published maps and institutional affiliations.

(๑) The Author(s), under exclusive licence to Springer Nature Limited 2021 


\section{Methods}

Historical data. The analysis builds upon yearly power generation data until 2019 from $\mathrm{BP}^{6}$. Power sector data from Ember for the first half of 2020 for a subset of countries, representing roughly three-quarters of global power generation, is shown in Fig. 1b for comparison'. Data on $\mathrm{CO}_{2}$ emissions for 2011-2018 are from the IEA ${ }^{10}$, and 2019 data are deduced from the generation data in the BP dataset, assuming constant emissions factors by fuel.

Projections based on yearly generation estimates. The projections of total demand (and total power generation) in 2020 and 2021 are based on GDP projections by the $\mathrm{IMF}^{8}$, assuming an elasticity of electricity demand to GDP of 0.6. Demand projections for 2022-2024 assume the average value of 2011-2019 demand increases, resulting in a number comparable to yearly demand increases in the IEA's stated policies scenario ${ }^{10}$.

The projections for increased generation from low-carbon technologies for 2020-2024 assume a continuation of the linear trend observed from 2017-2019, with a once-off $40 \%$ reduction in the year 2020 to account for the reduced output of nuclear power plants observed in the data for the first half of 2020, as well as interruptions in renewable installations in March and April.

For the projection of emissions in 2020-2024, we distinguish between uncertainty about volumes of fossil generation (being determined by growth of total demand and low-carbon generation) and uncertainty about the composition and thus emissions intensity of fossil generation (being a question of relative prices). The central three trajectories (red and inner grey lines) are all based on the central estimate on development of fossil generation as displayed in Fig. 1a,b. The higher grey line assumes that the emissions intensity of fossil generation stays constant at 2019 levels, as used in previous studies ${ }^{26}$, while the lower grey line assumes that all generation reductions are taken up by coal generation, which seems to be more in line with data from the USA, India and Europe (Extended Data Fig. 2). The central red line takes an intermediate assumption, namely that the emissions intensity of displaced fossil generation is the mean between the intensity of fossil generation and coal power generation. Additionally, a very high (and a very low) emissions estimate result from assuming fossil generation to be higher (or lower) than in the central estimate, by 200, 400, 800, 1,200 and 1,600 TWh in years 2020-2024, respectively. This reflects the uncertainties about growth of both demand and low-carbon generation, which is on the order of a few hundred TWh each and increases over time. The very high estimate assumes constant emissions intensity of fossil generation, while the very low one assumes all reductions to be from coal generation. Average emissions intensities of generation for both gas and coal are assumed to remain at 2019 levels, while in reality they might continue to improve in 2020 over the next years, due to higher variable generation costs of older and less efficient plants.

Comparison with estimates from daily model based on confinement by Le Quéré et al.. The original model by Le Quéré et al. ${ }^{1}$ assumed no emissions reductions for the power sector for level 1 confinement in the low, medium or high specification. We replicated a simpler version of their model (without disaggregation of China and the USA) that, using their specification, is able to replicate the economy-wide yearly reductions mentioned in their paper, and used this to calculate the power sector emissions reductions mentioned above in Main (as the paper and supplementary information of Le Quéré et al. ${ }^{1}$, while showing them in graphs, do not specify numbers for the relative yearly reduction per sector). We then adjusted the specifications on sectoral reduction per confinement level (Supplementary Tables 1 and 2) to match the observed emissions reductions in the power sectors of the EU, India and the USA (Supplementary Figs. 1 and 2), arriving at an updated estimate that broadly matches the alternative top-down methodology from Fig. 1.
Further details on the projections in Fig. 1 and comparisons with different specifications of the daily model from Le Quéré et al. ${ }^{1}$ can be found in the Supplementary Information.

\section{Data availability}

Power generation data for years up to 2019 are available at https:/www.bp.com/ content/dam/bp/business-sites/en/global/corporate/xlsx/energy-economics/ statistical-review/bp-stats-review-2020-all-data.xlsx. Power generation data for the first half of 2020 are available at https://ember-climate.org/wp-content/ uploads/2020/08/Ember-Global-Electricity-Review-2020-half-year-data.xlsx. Hourly/daily generation data for Europe, the USA and India are available at https://transparency.entsoe.eu/, https://www.eia.gov/opendata/ and www. carbontracker.in and https://power.carboncopy.info/. GDP projections for 2020 and 2021 are available at https://www.imf.org/en/Publications/WEO/ Issues/2020/09/30/world-economic-outlook-october-2020. Data on $2019 \mathrm{CO}_{2}$ emissions and 2020 confinement indices are available at https://www.icos-cp.eu/ gcp-covid19. Source data are provided with this paper.

\section{Code availability}

All code used for data analysis and creating the figures is available at https://github. $\mathrm{com} /$ christophbertram/covid-power-sector ${ }^{25}$.

\section{References}

25. Bertram, C. et al. Repository: COVID-induced low power demand and market forces starkly reduce $\mathrm{CO}_{2}$ emissions. Zenodo https://doi.org/10.5281/ zenodo.4453371 (2021).

26. Liu, Z. et al. Near-real-time monitoring of global $\mathrm{CO}_{2}$ emissions reveals the effects of the COVID-19 pandemic. Nat. Commun. 11, 5172 (2020).

\section{Acknowledgements}

C.B. was supported by the European Union's Horizon 2020 research and innovation programme under grant agreement no. 821471 (ENGAGE). N.B. acknowledges funding from the German Federal Ministry of Education and Research (BMBF) in the Funding Priority 'Economics of Climate Change' (PEGASOS: 01LA1826C).

\section{Author contributions}

C.B. designed the study, with input from G.L., F.C., N.B. and F.U. C.B. and A.M. performed the analysis and produced the figures. C.B. designed the figures and wrote the manuscript with input from all co-authors.

\section{Competing interests}

The authors declare no competing interests.

\section{Additional information}

Extended data is available for this paper at https://doi.org/10.1038/s41558-021-00987-x.

Supplementary information The online version contains supplementary material available at https://doi.org/10.1038/s41558-021-00987-x.

Correspondence and requests for materials should be addressed to C.B.

Peer review information Nature Climate Change thanks Aleh Cherp and the other, anonymous, reviewer(s) for their contribution to the peer review of this work.

Reprints and permissions information is available at www.nature.com/reprints. 
a Total generation (TWh) in OECD

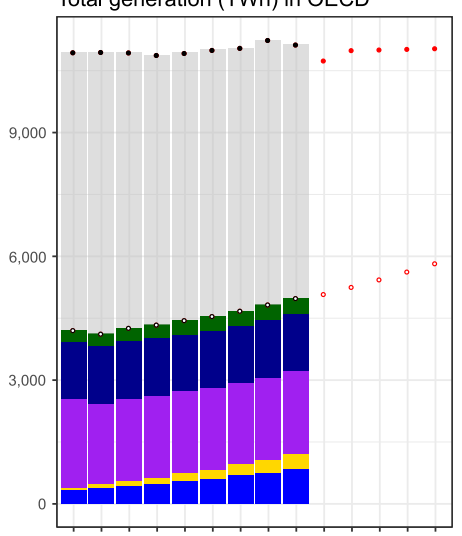

c Total generation (TWh) in China

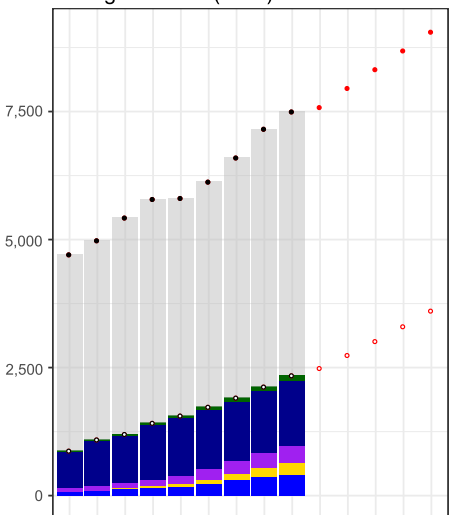

e Total generation (TWh) in India

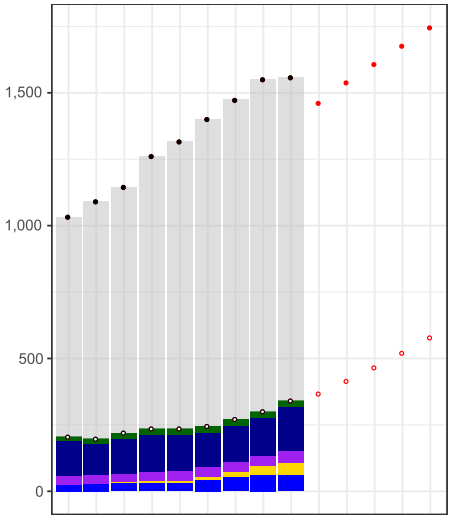

g Total generation (TWh) in Rest of World

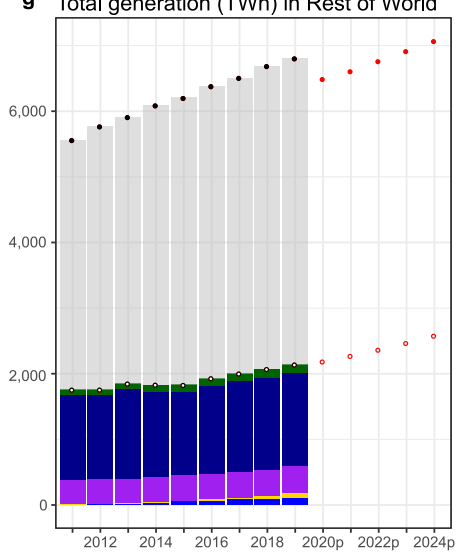

b Year-on-year changes (TWh) in OECD

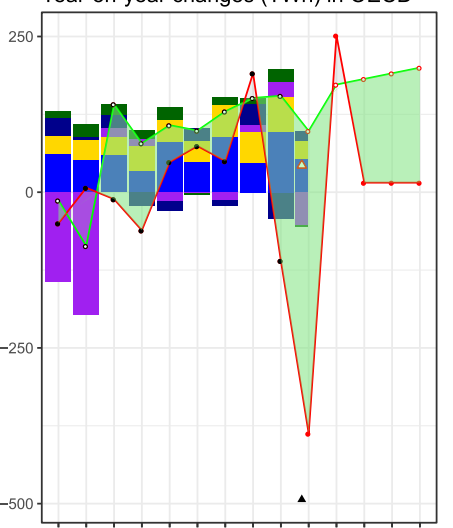

d Year-on-year changes (TWh) in China

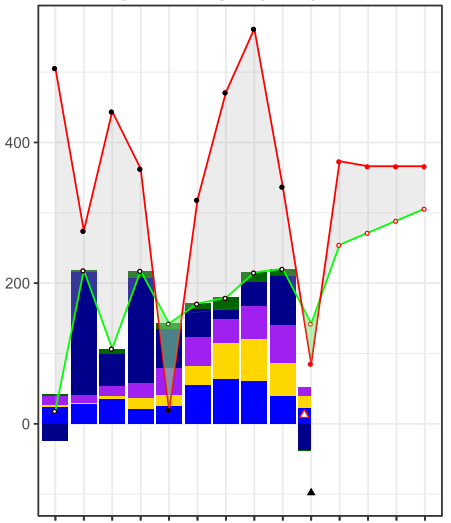

f Year-on-year changes (TWh) in India

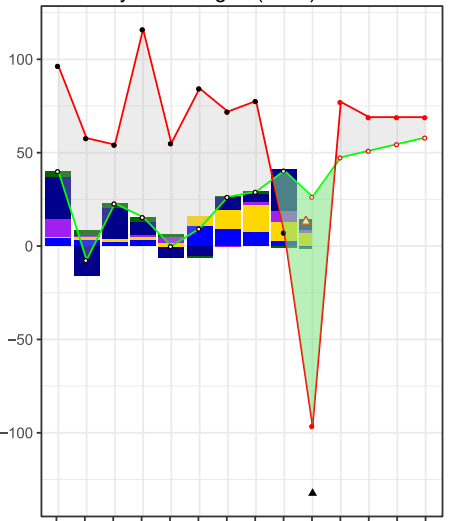

Demand change

$\rightarrow$ Change

$\therefore$ Projected values

(Change in)

fossil generation

Increase/absolute

Decrease

Preliminary data

for H1 2020 from EMBER

$\Delta$ low-carbon addition in

H1 2020

Implied demand change

for fulll year (scaled to

total demand in
Rest of World)

h Year-on-year changes (TWh) in Rest of World

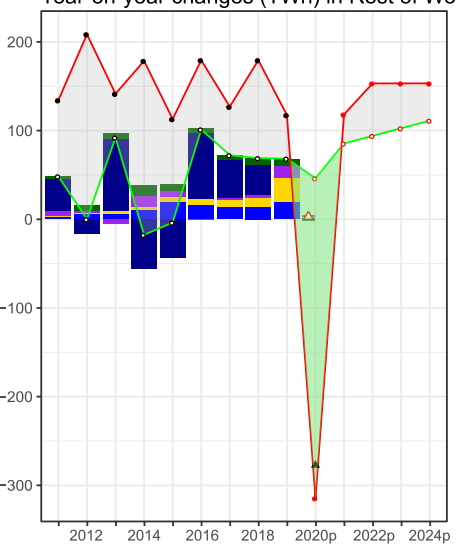

Extended Data Fig. 1 | See next page for caption. 
Extended Data Fig. 1 | Historical evolution of regional power generation and plausible pathways showing an illustrative disaggregation of global numbers for the years 2020-2024. Left column: Absolute values for each year. Right column: Yearly changes of power generation by individual low-carbon technologies (colored bars), their total net change (white dots and green line), and total power generation as proxy for demand (black dots and red line). The colored areas indicate increases of residual fossil generation (grey) and decreases (green). See methods for data sources and assumptions behind projections. 

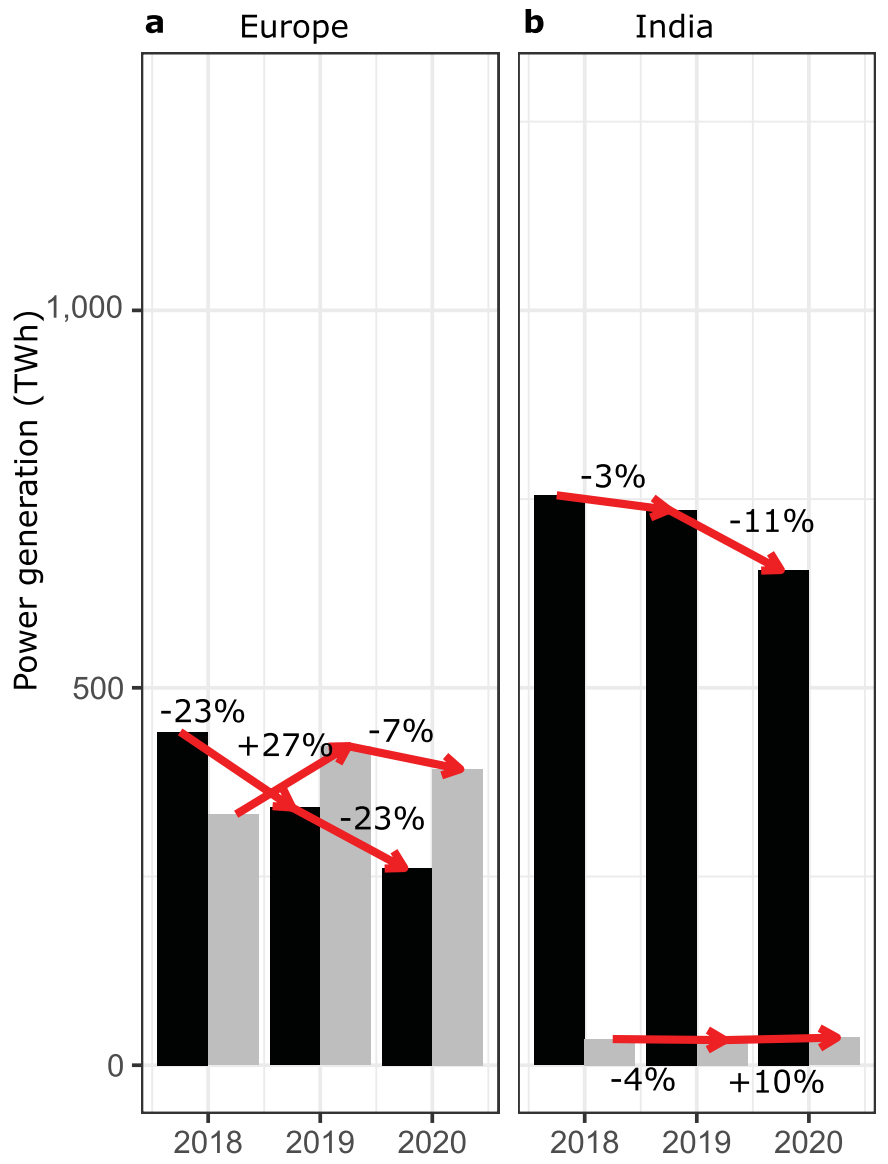

C

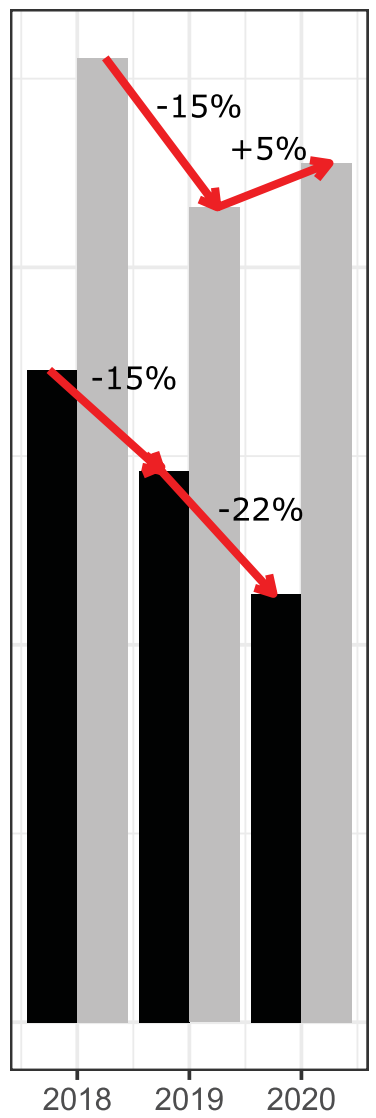

Coal

Gas

Extended Data Fig. 2 | Comparison of power generation from coal and natural gas for first nine months of 2018, 2020 and 2019, in Europe, India and the US. Data for Europe includes all countries on the ENTSO-E transparency platform, and compares data until October 1 in 2020 vs. data until September 30 in 2019 (to account for the leap year). Coal includes lignite and hard coal. Data for the US represents generation in the lower 48 states. Data for India is from https://power.carboncopy.info/ and shows a combined category for 'Gas', including natural gas, naphta and diesel. 2018 data for USA and India is inferred from the yearly totals for 2018 and 2019 from BP, as the daily information used for 2019 and 2020 is not available for 2018. 


\section{Emission intensity of power generation ( $\left.\mathrm{C} \mathrm{CO}_{2} / \mathrm{MWh}\right)$}

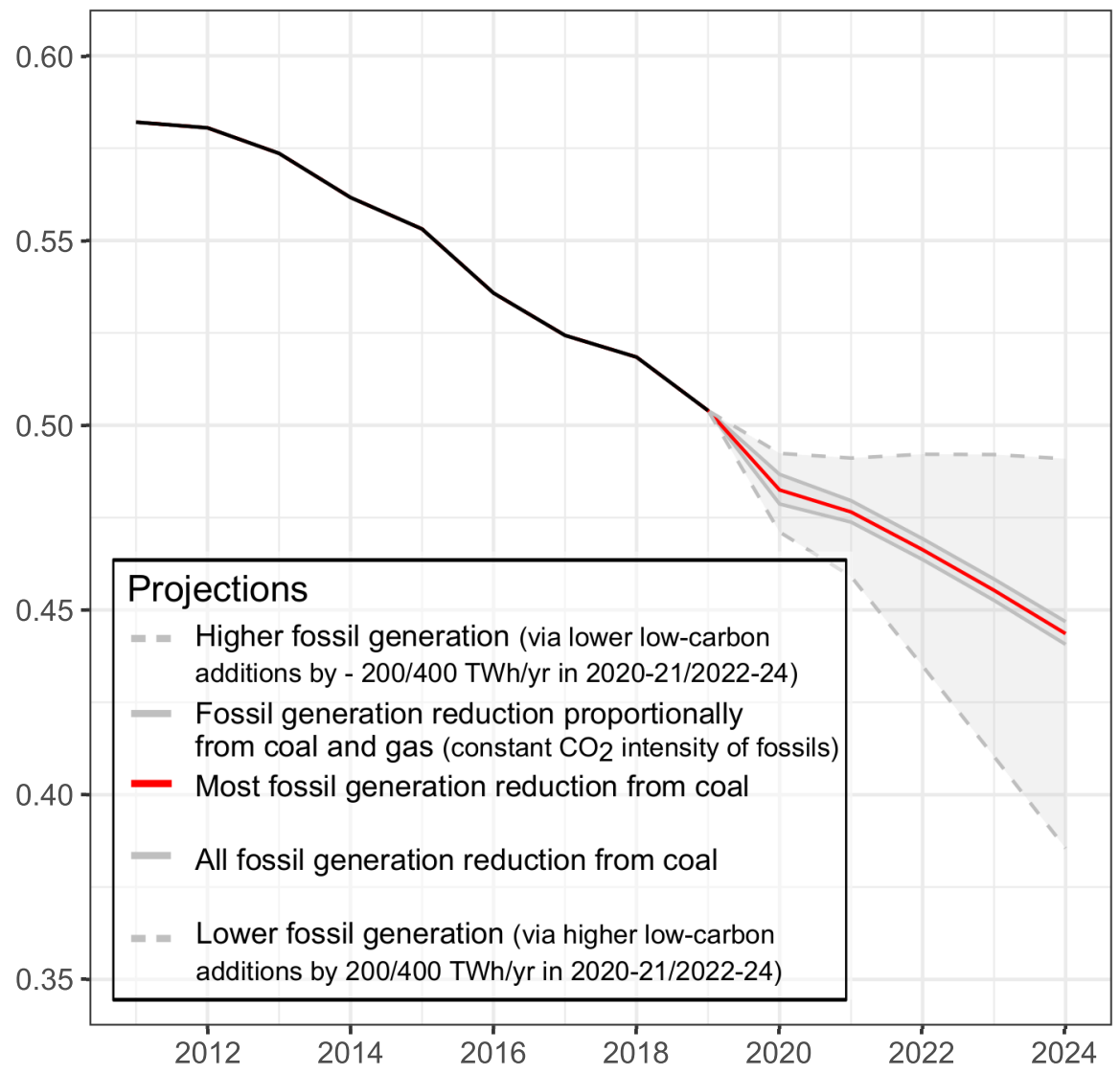

Extended Data Fig. 3 | Emission intensity of power generation in last decade and projections for next years. Based on projections in panel 1c of main paper, assuming slower and faster low-carbon generation growth for extreme projections. Please note that the $y$-axis scale does not start at zero. 